\title{
The effect of coaching behaviors on tennis players and swimmers
}

\author{
Cengiz C. ${ }^{\mathrm{ABCDE}}$, Serbes Ş. ${ }^{\mathrm{ABCD}}$, Erdoğan Ö. ${ }^{\mathrm{AB}}$, Dağ Ş. ${ }^{\mathrm{AB}}$ \\ Department of Teaching Physical Education and Sport, Çanakkale onsekiz Mart University, Turkey
}

Authors' Contribution: A - Study design; B - Data collection; C - Statistical analysis; D - Manuscript Preparation; E - Funds Collection.

\begin{tabular}{|c|c|}
\hline \multicolumn{2}{|l|}{ Abstract } \\
\hline Purpose: & $\begin{array}{l}\text { The purpose of the current research is to investigate tennis players and swimmers' perceived coaching } \\
\text { behaviors for sport with sport age. }\end{array}$ \\
\hline Material: & $\begin{array}{l}\text { A cross-sectional survey method was applied to tennis players and swimmers (Buyukozturk et al., 2012). } \\
\left.\text { Participants ( } n_{\text {females }}=175 ; n_{\text {males }}=187\right) \text { were selected from different tennis }(n=122) \text { and swimming }(n=240) \\
\text { clubs in Canakkale, Istanbul and Hatay provinces. For data collection, a translated Turkish version (Yapar } \\
\text { et al., 2014) of the Coaching Behavior Scale for Sport (CBS-S) (Côté et al., 1999) was used. The CBS-S } \\
\text { includes } 47 \text { items and } 7 \text { sub-dimensions. The collected data were analyzed with descriptive and One-Way } \\
\text { Analysis of Variance (ANOVA) statistics. The CBS-S sub-dimensions were evaluated with the sport age of } \\
\text { tennis players and swimmers }(p<.05) \text {. }\end{array}$ \\
\hline Results: & $\begin{array}{l}\text { According to the One-Way ANOVA, sport age was statistically significant in the sub-divisions of physical } \\
\text { training and condition, technical skills, mental preparation, goal setting, competition strategies and } \\
\text { personal rapport among tennis players }(p<.05) \text {. Among swimmers, sport age was significant for only } \\
\text { negative personal rapport }(p<.05) \text {. }\end{array}$ \\
\hline Conclusions: & $\begin{array}{l}\text { Tennis players and swimmers' perceived Coaching Behavior for Sport scores were evaluated as high. } \\
\text { Sport age was significant for the Coaching Behavior for Sport sub-dimensions among tennis players. } \\
\text { coaching behavior, individual sports, sport age. }\end{array}$ \\
\hline
\end{tabular}

\section{Introduction}

Training can be referred to as a preparation process intended to maximize athletes' performance [1]. It is certain that coaches play a crucial role in this process. They serve as planners and directors in the development of such special qualifications as multilateral physical development, allowing for the implementation of tasks in training, sports-specific physical development, technical skills, tactical abilities, psychological characteristics, preservation of health, avoidance of injuries, institutional knowledge, etc. Moreover, coaches are expected to hold a knowledge of pedagogical approaches and training methods that addresses the needs of athletes [2]. Harrison et al. [3] report that coaching incorporates complex and ongoing experiences for athletes, coaches, and training settings, and that a coach stands out as the fundamental figure in the training setting [4, 5]. Mallet [6] remarks that the sport setting basically consists of a network of interactions between coach, athlete and training setting, and that it is complicated and demands strenuous effort to understand because of its social and dynamic structure.

The relationship between the athlete and the coach in the sport setting is important for both the psychosocial and physical development of athletes [7]. The coach is a role model for young athletes and has a considerable influence on them [8]. Coach behaviors play a critical role in the development of skills needed for an athlete's motivation and performance. The results of previous research studies have revealed that coaching behaviors are the most important factors in determining the quality of an individual's relationship with sports [9, 10, 11]. Generally, the success of coaches is evaluated based on the

๔) Cengiz C., Serbes Ş., Erdoğan Ö., Dağ Ş., 2019

doi:10.15561/18189172.2019.0303 won competitions, the number of medals, and the number of players called up to national teams or transferred to a senior league. Many national or senior coaches receive financial support from various sources in view of their achievements, or their contracts are terminated in the event of failure [12]. However, some researchers note that assessment of coaches solely based on their achievements or failures is not a sufficient and effective method [13].

A great number of models concerning the network between coaches, athletes and training setting have been produced [14] among gymnastic coaches [15], youth sports' coaching behavior during training session [16], youth sport attrition [17], baseball coaches [18], youth basketball coaches [19]. In addition, coach behaviors have been investigated in the training settings of various disciplines such as expert basketball coaches [20], social analyses of coaching [21], soccer coaches [22], and volleyball coaches [23]. One of the coaching models was developed by Cote et al. [24]. This model was based on Coaches' Knowledge, which outlines three main knowledge types: (a) Professional (sport specific) knowledge, which includes technical, tactical, mental, pedagogical, training, nutrition, etc.; (b) Interpersonal knowledge, which refers to individual and group interactions with children, adolescents, and adults (e.g. coach-athletes relationships); (c) Intrapersonal knowledge, which refers to ongoing learning and reflection. Research attempting to account for the complex network between coach, athlete, and training pattern in a sport setting has shown that coach behaviors directly affect an athlete's development in terms of leadership style [14], gymnastic coaching behavior [15], coaching behavior during training [16], coach-athlete behaviors [25], and youth basketball context [26]. The skill acquisition processes 
of elite athletes, practice activities and coach behaviors have been investigated in different studies [27, 28], and these have offered suggestions as to how a coach should behave (type of feedback, training style, etc.). This was summarized by Partington, Cushion and Harvey [29] in relation to studies into the age variable with respect to how coaches' behaviors are influenced by experience and peripheral factors, and by Sagar and Jowett [30] on how age exerts more profound effects on the fear of failure.

Coaching behavior research has been widely examined with various ages, levels, and contexts [31,32], supporting the important and pertinent aspects of coaching. The Coaching Behavior Scale (CBS), after extensive review, has been found to be a reliable and valid instrument in the literature; among athletes from 15 different sports [33], team and individual sports [34], coach-athlete relationship in different sports were examined qualitatively [35], Singaporean youth athletes [36], Swedish athletes [37], volleyball players [38] and Indian athletes [39]. The CBS demonstrated that each category is crucial and valuable when evaluating a coach's behavior. In addition, college athletes' perceptions of coaching behavior in individual and team sports were evaluated by Aleksic-Veljkovic et al. [40]. It is reported that individual athletes' perceptions of coaches were higher than those of team sport athletes in training and instruction, social support and positive feedback. Similarly, Rhind et al. [41] reported that individual athletes perceived their coach as closer, more committed and complimentary. Baker, Yardley and Cote [34] assessed individual and team sport members with the CBS. The findings showed that high coaching satisfaction for athletes in team sports is influenced to a greater extent by the demonstration of these behaviors, as opposed to the case of individual sport athletes. Research on aquatic or racquet sports has been limited, however.

On the other side, a scarce number of studies on this subject matter exist for the case of Turkey, and those that exist were found to concern adaptation-oriented efforts $[12,25]$ and to have analyzed coach behaviors $[26,42,43]$. Coach behaviors as a current issue, which are decisive in young athletes' engagement in sports and achievements, have been highly influential in efforts to retrieve more data on coaches in sport settings, relationships between athletes and coaches, and a complicated network of relations in a training setting [44]. Accordingly, the present study is intended to investigate the effect of perceived coaching behaviors on tennis players and swimmers based on the sport age. It builds on the hypothesis that tennis players and swimmers positively perceived coach behaviors based on the sport age.

\section{Material and Methods}

Participants: The ages of participants, and the mean and standard deviation of their sport ages were calculated (Female Tennis players Mage $=13.09$, SDage $=2.08$; Male Tennis Players Mage $=13.28$, SDage $=2.01$ ) and (Female Swimmers Mage $=13.92$, SDage $=0.82$; Male Swimmers Mage $=13.91$, SDage $=0.79$ ).

Research Design: A cross-sectional survey method was applied in the study [45]. A sample of the research $(n=362)$ was based on swimmers and tennis players from Canakkale $(\mathrm{n}=119)$, Istanbul $(\mathrm{n}=121)$ and Hatay $(\mathrm{n}=122)$ provinces (Girls $=175$; Boys $=187$ ).

Measures: The Coaching Behavior Scale for Sport (CBS-S): The instrument was developed by Cote, Yardley, Hay, Sedgwick and Baker [35], and a Turkish version was validated by Yapar and Ince [12]. The items on the scale are related to athletes' comments about physical training and conditioning, technical skills, mental preparation, goal setting, competitive strategies and positive/negative personal rapport. The CBS-S includes 47 items and 7 subdimensions. Each item is rated on a 7-point likert-type scale.

There are 6 sub-dimensions under positive personal rapport and one negative personal rapport dimension on the scale. The sub-dimensions under positive personal rapport were 1) Physical Training and conditions, 2) Technical Skills, 3) Mental Preparation, 4) Goal Setting, 5) Competition Strategies, 6) Personal Rapport, and one negative personal rapport item.

Data Collection: The researchers contacted the club coaches and managers, and determined the appropriate days and times to conduct the study. An informed consent form was obtained from parents and coaches after ethical permission was granted. The scale was applied by the researchers before or after a training period or competition during the spring semester, which is the beginning of the season. Participation was on a volunteer basis; participants could leave at any time by request. The application of the scale lasted approximately 10 minutes. Participants' sport age was summarized in Table 1 according to their gender.

Statistical Analyses: The collected data were analyzed through descriptive and Analysis of Variance (ANOVA) models after assumption check was provided. ANOVA was applied for each sport with $(p<0.05)$ as the alpha level.

\section{Results}

Descriptive statistics for tennis players and swimmers were reported in Table 2 based on the CBS-S and subscales.

According to the Analysis of Variance (ANOVA) (Table 3), swimmers' sport age and the CBS-S subdimension negative personal rapport were significantly related $[\mathrm{F}(1,10=2.27, \mathrm{p}=0.01]$. On the other hand, tennis players' sport age, except the negative personal rapport $[\mathrm{F}(1,6=1.63, \mathrm{p}=0.14]$ sub-dimension, were significantly related to physical training and condition $[\mathrm{F}(1,6=5.05$, $\mathrm{p}=0.00]$, technical skills $[\mathrm{F}(1,6=5.92, \mathrm{p}=0.00]$, mental preparation $[\mathrm{F}(1,6=3.71, \mathrm{p}=0.00]$, goal setting $[\mathrm{F}(1$, $6=4.84, \mathrm{p}=0.00]$, competition strategies $[\mathrm{F}(1,6=5.69$, $\mathrm{p}=0.00]$ and positive personal rapport $[\mathrm{F}(1,6=4.44$, $\mathrm{p}=0.00]$. For the significant difference in every sport age group, further analyses (Post Hoc, Turkey HSD test) for each sub-scale were applied, and the age groups' mean and standard deviation were reported.

A significant difference was detected on the physical training and condition sub-scale sport age $5(\mathrm{M}=4.63$, 
Table 1. Participants' sport age based on gender and their percentages.

\begin{tabular}{lllll}
\hline Sport age & $\begin{array}{l}\text { Female } \\
(\mathbf{n = 1 7 5 )}\end{array}$ & Percentage (\%) & $\begin{array}{l}\text { Male } \\
(\mathbf{n = 1 8 7})\end{array}$ & Percentage (\%) \\
\hline 1 & 48 & 27.4 & 59 & 31.7 \\
2 & 36 & 20.6 & 35 & 18.8 \\
3 & 25 & 14.3 & 26 & 13.9 \\
4 & 21 & 12.0 & 29 & 15.0 \\
5 & 15 & 8.6 & 10 & 5.4 \\
6 & 14 & 8.0 & 15 & 8.0 \\
7 & 7 & 4.0 & 6 & 3.3 \\
8 & 4 & 2.3 & 5 & 2.8 \\
9 & 2 & 1.1 & 2 & 1.1 \\
\hline
\end{tabular}

Table 2. Tennis players and swimmers' perceived CBS-S sub-scales mean and standard deviation values.

\begin{tabular}{lllll}
\hline Sub-scales & $\begin{array}{l}\text { Tennis Players } \\
(\mathbf{n = 1 2 2})\end{array}$ & \multicolumn{3}{c}{$\begin{array}{l}\text { Swimmers } \\
(\mathbf{n = 2 4 0})\end{array}$} \\
& $\mathbf{M}$ & SD & $\mathbf{M}$ & SD \\
\hline Physical Training and Condition & 5.92 & 0.76 & 5.28 & 1.17 \\
Technical Skills & 6.32 & 0.96 & 5.67 & 1.17 \\
Mental Preparation & 6.17 & 1.21 & 5.35 & 1.31 \\
Goal Setting & 6.10 & 1.01 & 5.44 & 1.24 \\
Competition Strategies & 6.32 & 0.96 & 5.56 & 1.25 \\
Positive Personal Rapport & 6.13 & 1.14 & 5.10 & 1.64 \\
Negative Personal Rapport & 2.85 & 1.69 & 2.28 & 1.32 \\
Total CBS-S & 39.82 & 4.82 & 34.69 & 6.57 \\
\hline
\end{tabular}

Table 3. Tennis players and swimmers' perceived CBS-S sub-dimensions ANOVA results.

\begin{tabular}{lllllllll}
\hline \multirow{2}{*}{ Sub-dimensions } & \multicolumn{3}{c}{ Tennis Players $(\mathbf{n}=\mathbf{1 2 2})$} & \multicolumn{4}{c}{ Swimmers $(\mathbf{n}=\mathbf{2 4 0})$} \\
& $\mathbf{d f}$ & $\mathbf{F}$ & $\mathbf{\eta}^{\mathbf{2}}$ & $\mathbf{p}$ & $\mathbf{d f}$ & $\mathbf{F}$ & $\mathbf{\eta}^{\mathbf{2}}$ & $\mathbf{p}$ \\
\hline Physical Training and Condition & 6 & 5.05 & 0.21 & $0.00^{*}$ & 10 & 1.01 & 0.04 & 0.43 \\
Technical Skills & 6 & 5.92 & 0.24 & $0.00^{*}$ & 10 & 0.82 & 0.03 & 0.61 \\
Mental Preparation & 6 & 3.71 & 0.16 & $0.00^{*}$ & 10 & 1.06 & 0.04 & 0.39 \\
Goal Setting & 6 & 4.84 & 0.20 & $0.00^{*}$ & 10 & 0.64 & 0.03 & 0.77 \\
Competition Strategies & 6 & 5.69 & 0.23 & $0.00^{*}$ & 10 & 0.65 & 0.03 & 0.78 \\
Positive Personal Rapport & 6 & 4.44 & 0.19 & $0.00^{*}$ & 10 & 0.92 & 0.04 & 0.51 \\
Negative Personal Rapport & 6 & 1.63 & 0.08 & 0.14 & 10 & 2.27 & 0.09 & $0.01 *$ \\
Total CBS-S & 6 & 4.73 & 0.20 & $0.00^{*}$ & 10 & 0.85 & 0.04 & 0.58 \\
\hline
\end{tabular}

$* p<0.05$

$\mathrm{SD}=1.51$ ) among tennis players, which showed lower scores than sport age $1(\mathrm{M}=6.04, \mathrm{SD}=0.70)$. In technical skills sport age $5(\mathrm{M}=4.68, \mathrm{SD}=2.02)$ showed lower scores than sport age $2(\mathrm{M}=6.44, \mathrm{SD}=0.52)$; mental preparation sport age $5(\mathrm{M}=5.50, \mathrm{SD}=1.97)$ showed lower scores than sport age $3(\mathrm{M}=5.84, \mathrm{SD}=1.24)$; goal setting sport age $5(\mathrm{M}=4.64, \mathrm{SD}=1.96)$ showed lower scores than sport age $4(\mathrm{M}=6.08, \mathrm{SD}=0.65)$; competition strategies sport age $5(\mathrm{M}=4.63, \mathrm{SD}=1.90)$ showed lower scores than sport age $1(\mathrm{M}=6.49, \mathrm{SD}=.90)$, sport age $2(\mathrm{M}=6.40$, $\mathrm{SD}=0.70)$, sport age $3(\mathrm{M}=6.42, \mathrm{SD}=0.60)$, sport age 4 $(\mathrm{M}=6.57, \mathrm{SD}=0.43)$, and sport age $6(\mathrm{M}=5.60, \mathrm{SD}=0.14)$. Lastly, the positive personal rapport sub-scale sport age 5 $(\mathrm{M}=4.55, \mathrm{SD}=0.07)$ showed lower scores than sport age 1 $(\mathrm{M}=6.31, \mathrm{SD}=1.08)$.

\section{Discussion}

The findings of the research revealed that the 
tennis players and swimmers considered their coaches' behaviors to be highly positive, and that age of athlete is influential in the evaluations concerning coach behaviors. It was found that tennis players assigned a higher score to the perceived behaviors of coaches than swimmers did. As reported by the tennis players, age was discovered to be significant in all sub-domains except for the negative behaviors of coaches. The literature review showed that scientific studies into coach behaviors were very limited in number, and further research is needed in relation to this subject matter. As a result, the discussion was built on exiguous studies.

In this investigation into coach behaviors as perceived by athletes of varying ages, it was observed that coach behaviors were evaluated differently depending on the athlete's age. It is thought that this difference might have been caused by training content and coach's approach, as well as care during training. Future research is suggested to systematically observe coach behaviors in different sports.

The literature on coach behaviors, for example Claxton [46], found that successful tennis coaches asked more questions to players than unsuccessful ones did. In the study by Rupert and Buschner [47] comparing the teaching behaviors of baseball coaches and faculty members teaching at universities, it was observed that coaches achieved higher average scores in the preteaching, motivation, and silence dimensions than faculty members did, while faculty members scored higher in management and other categories than coaches did. In the study by Becker and Wrisberg [48], the practices of coaches are systematically analyzed. The findings indicate that the most frequently repeated behaviors of coaches are instruction, followed by encouragement and quick moves. Yapar [26] conducted a study on recreational and performance-oriented basketball schools, in which he observed that coaches exhibited instructional behaviors in both basketball settings, which were followed by encouraging and supportive behaviors.

Sagar and Jowet [30] express that age and gender exert profound effects on fear of failure in individual and team sports. The research suggests that team athletes feel more anxious than individual athletes do. Coaches training young team athletes are reported to allocate more time to skills acquisition and game instructions during coaching. In the present study, statistically significant differences were observed in the sub-domain "acquisition of technical skills" depending on the age of sport participation. The rationale behind this finding was considered to rest in the age of athletes and their need for more pre-teaching in comparison with more experienced athletes [26]. In addition to CBS-S validity and reliability research in different nations and various sport types; in Turkish context [12], among athletes from 15 different sports [33], coach-athlete relationship in different sports were examined qualitatively [35], Singaporean youth athletes [36], Swedish athletes [37], volleyball players [38] and Indian athletes [39]. Baker et al. [34] examined individual and team sport members. The results showed higher coaching satisfaction among athletes in team sports than among individual sport athletes. Differently, in the current research tennis players were affected more than swimmers based on sport age. It can be concluded that sport age is an important variable when evaluating the coach and athlete relationship.

Unlike the findings of this research, there are findings that age of athletes is nota significant variablein determining coach behaviors. Partington et al. [29] reported in their qualitative research that role expectation and experience are significant variables, and that pressure by a parental audience affects the behaviors of less experienced and less knowledgeable coaches. Consequently, they suggest that coaches are affected more by peripheral factors than by the age-related developmental needs of athletes.

One of the important findings of the research is that age of sport participation has an effect on the evaluation of coach behaviors. It can be asserted that children appreciate coaching behaviors more as age of participation increases. Junior basketball players were found to assess their coaches' behaviors positively, and age of participation and gender to affect the sub-domains "training and fitness, competition strategies and goal setting, positive coach behaviors" [42, 43]. Avoidance of negative coaching behaviors is of great importance, especially when training children. Encouraging and motivating children during coaching and providing them with positive feedback play a significant part in their psychosocial development and positive personality development. Barnett et al. [17], Jagiello et al. [49, 50], Kriventsova et al. [51] and Smith et al. $[18,19]$ discovered that coach behaviors affected such psychological properties of athletes as self-esteem, satisfaction level and perceived abilities.

\section{Conclusions}

The results of the present study are considered to make substantial contributions to prospective and active coaches and teachers of physical education in training competent athletes. Specifically, the athlete and coach relationship needs to be designed according to sport age and athletes' specific needs based on short or long term goals. Notably, positive rapport and ways of improving rapport will help enhance athlete performance. There is need in the field for a greater number of and more detailed observations concerning coach behaviors. In view of the findings of this research study, it is deemed important that young athletes positively evaluated their coaches, and it is suggested that the subject should be researched based on observations in actual settings. In addition, future research should concentrate on physical training and condition, technical skills, mental preparation, goal setting, competition strategies and personal rapport according to the sport ages of tennis players and swimmers in experimental research. The effect of coaching experience on athletes can also be investigated using qualitative research design.

\section{Conflict of interests}

The authors declare that there is no conflict of interests. 


\section{References}

1. Bompa TO. Periodization Theory and Methodology of Training (Eds.) Ankara: Sport Publication; 2015.

2. Ford P, Williams A. The acquisition of skill and expertise: The role of practice and other activities. Sci and Soccer, 2013; 3: 122-138.

3. Harrison JM, Preece LA, Blakemore CL, Richards RP, Wilkinson C, Fellingham GW. Effects of two instructional models - Skill teaching and mastery learning - on skill development, knowledge, self-efficacy, and game play in volleyball. J Teach Phys Educ. 1999; 19(1): 34-57. https://doi.org/10.1123/jtpe.19.1.34

4. Cushion C, Jones RA. Systematic observation of professional top-level youth soccer coaches. J Sport Behav. 2001; 24(4): 354-376.

5. Mesquita I, Sobrinho A, Rosado A. A systematic observation of youth amateur volleyball coaches behaviours. Int $J$ Appl Sport Sci, 2008; 20(2): 37-58.

6. Mallett CJ. Modelling the complexity of the coaching process: A commentary. Int J Sport Sci Coach. 2007; 2(4): 407-409.

7. Jowett S, Cockerill IM. Olympic medallists' perspective of the athlete-coach relationship. Psychol Sport Exerc. 2003; 4(4): 313-331. https://doi.org/10.1016/S1469-0292(02)00011-0

8. Smoll FL, Smith RE. Conducting sport psychology training programs for coaches: Cognitive-behavioral principles and techniques. In: J. M. Williams (Ed.), Applied sport psychology: Personal growth to peak performance (5th ed.). Boston: McGraw-Hill; 2006. P. 458-480.

9. Malina RM, Clark MA. Youth sports: Perspectives for a new century. Monterey: Coaches Choice; 2003: 109-126.

10.Smoll FL, Smith RE. Children and youth in sport: $A$ biopsychosocial perspective. Dubuque: Kendall/Hunt; 2002.

11. Weiss M. Developmental sport and exercise psychology: A lifespan perspective. Morgantown: Fitness Information Technology; 2004.

12. Yapar A. Ince ML. The adaptation of coaching behavior scale for sport (CBS-S) into Turkish: A validity and reliability study. Hacettepe J Sport Sci. 2014; 25(4): 203-212.

13. Mallett CJ, Côté J. Beyond winning and losing: Guidelines for evaluating high performance coaches. Sport Psychol. 2006; 20(2): 213-221. https://doi.org/10.1123/tsp.20.2.213

14.Chelladurai P. Leadership in Sport. In: J.M. Silva, R.S. Weinberg (Eds.) Psychological foundations of sport. Champaign, IL; Human Kinetics; 1984. P. 329-339.

15. Côté J, Salmela JH, Trudel P, Baria A, Russell SJ. The coaching model: A grounded assessment of expertise gymnastic coaches' knowledge. J Sport Exer Psychol. 1995; 17(1): 1-17. https://doi.org/10.1123/jsep.17.1.1

16.Smoll FL, Smith RE. Leadership research in youth sports. In: J.M. Silva III \& R.S. Weinberg (Eds.), Psychological foundations of sport. Champaign, IL: Human Kinetics; 1984. P. 371-386.

17.Barnett NP, Smoll FL, Smith RE. Effects of enhancing coach-athlete relationships on youth sport attrition. Sport Psychol. 1992; 6: 111-127. https://doi.org/10.1123/tsp.6.2.111

18.Smith RE, Smoll FL, Curtis B. Coaching behaviors in little league baseball. In: F.L. Smoll RE, Smith (Eds.), Psychological perspectives in youth sports. Washington, DC: Hemisphere; 1978. P. 173-201.

19.Smith RE, Zane NWS, Smoll FL, Coppel DB. Behavioral assessment in youth sports: Coaching behaviors and children's attitudes. Med Sci Sport Exer. 1983; 15: 208-214. https://doi.org/10.1249/00005768-198315030-00005

20.Bloom GA, Crumpton R, Anderson JE. A systematic observation study of the teaching behaviors of an expert basketball coach. Sport Psychol. 1999; 13(2): 157-170. https://doi.org/10.1123/tsp.13.2.157

21.Jones RL, Armour KM, Potrac P. Understanding the coaching process: A framework for social analysis, Quest, 2002; 54(1): 34-48. https://doi.org/10.1080/00336297.2002.10491765

22.Potrac P, Jones R, Armour K. 'It's all about getting respect': The coaching behaviors of an expert english soccer coach. Sport, Educ Soc. 2002; 7(2): 183-202. https://doi.org/10.1080/1357332022000018869

23.Zetou E, Amprasi E, Michalopoulou M, Aggelousis N. Volleyball coaches behavior assessment through systematic observation. J Human Sport Exer. 2011; 6(4): 585-593. https://doi.org/10.4100/jhse.2011.64.02

24.Côté J, Salmela, JH, Trudel P, Baria A, Russell S. The coaching model: A grounded assessment of expert gymnastics coaches' knowledge. J Sport Exer Psychol. 1995; 17: 1-17. https://doi.org/10.1123/jsep.17.1.1

25.Altintas A, Cetinkalp ZK, Asci FH. Evaluating the coachathlete relationship: Validity and reliability study. Hacettepe J Sport Sci. 2012; 23(3): 119-128.

26.Yapar A. Comparison of practice activities, coaching behaviors, and athletes' psychosocial outcomes in two youth basketball contexts. Unpublished Doctorate of Philosophy, Institute of Social Science, Middle East Technical University, Ankara: Turkey; 2016.

27.Farrow D, Baker J, MacMahon C. Developing sport expertise: researchers and coaches put theory into practice: Routledge; 2013: 249-255. https://doi.org/10.4324/9780203119914

28. Williams AM, Hodges NJ. Practice, instruction and skill acquisition in soccer: Challenging tradition. J Sport Sci. 2005; 23(6): 637-650. https://doi.org/10.1080/02640410400021328

29.PartingtonM,CushionC,HarveyS.Aninvestigationoftheeffect of athletes' age on the coaching behaviours of professional toplevel youth soccer coaches, J Sport Sci. 2014; 32(5): 403-414. https://doi.org/10.1080/02640414.2013.835063

30.Sagar SS, Jowett S. The effects of age, gender, sport type and sport level on athletes' fear of failure: implications and recommendations for sport coaches. Int J Coach Sci. 2012; 6(2): 61-82.

31.Côté J, Sedgwick W. Effective behaviors of expert rowing coaches: A qualitative investigation of Canadian athletes and coaches. Int Sport J. 2003; 7: 62-78.

32.Gilbert WD, Trudel P. Validation of the Coaching Model (CM) in a team sport context. Int Sport J. 2000; 4: 120-128.

33.Baker J, Côté J, Hawes R. The relationship between coaching behaviours and sport anxiety in athletes. J Sci Med Sport. 2000; 3(2): 110-119. https://doi.org/10.1016/S1440-2440(00)80073-0

34.Baker J, Yardley J, Côté J. Coach behaviors and athlete satisfaction in team and individual sports. Int J Sport Psychol. 2003; 34: 226-239.

35.Côté J, Yardley J, Hay J, Sedgwick W, Baker J. An exploratory examination of the coaching behaviour scale for sport. Avante. 1999; 5: 82-92.

36.Koh KT, Kawabata M, Mallett CJ. The Coaching Behavior Scale for Sport: Factor structure examination for Singaporean youth athletes. Int J Sort Sci Coach. 2014; 9(6): 1311-1324. https://doi.org/10.1260/1747-9541.9.6.1311

37.Carlsson A, Lundqvist V. The Coaching Behavior Scale for 
Sport (CBS-S): A psychometric evaluation of the Swedish version, Scand J Med Sci Sports. 2016; 26: 116-123. https://doi.org/10.1111/sms.12359

38.Jurko D, Tomljanović, M, Čular D. Initial validation of coaching behavior scales in volleyball. Sport SP. 2013; 10(1): 47-50.

39. Sharma R, Jain T, Singh A, Mehta K. The Coaching Behavior Scale for Sport (CBS-S): Factor structure examination for elite Indian sportsperson, Indian J Positive Psychol. 2018; 9(1): 1-8.

40.Aleksic-Veljkovic A, Djurovic D, Dimic I, Mujanovic R, Zivcic-Markovic K. College athletes' perceptions of coaching behaviours: differences between individual and team sports, Balt J Sport Health Sci. 2016; 2(101): 61-65.

41.Rhind DJA, Jowett S, Yang SX. A comparison of athletes' perceptions of the coach-athlete relationship in team and individual sports. J Sport Behav. 2012; 35(4): 433-452.

42.Serbes S, Erdogan O, Dag S. "Examination of tennis players and swimmers' coaching behaviors", Proceedings of 14th Annual Congress of International Sport Sciences, November 1-4, Antalya, Turkey; 2016. P.762.

43.Serbes S, Cengiz C, Burucu S. Examination of Coaching Behaviors of Basketball Players, Proceedings of 14th Annual Congress of International Sport Sciences, November 1-4, Antalya, Turkey; 2016. P.765.

44.Fraser-Thomas JL, Côté J, Deakin J. Youth sport programs: An avenue to foster positive youth development. Phys Educ Sport Peda. 2005; 10(1): 19-40. https://doi.org/10.1080/1740898042000334890
45.Buyukozturk S, Cakmak EK, Akgun OE, Karadeniz S, Demirel F. Scientific research methods (Eds.). Ankara: Pegem Akademi; 2012.

46.Claxton DB. A systematic observation of more and less successful high school tennis coaches. $J$ Teach Phys Educ. 1988; 7(4): 302-310. https://doi.org/10.1123/jtpe.7.4.302

47.Rupert T, Buschner C. Teaching and coaching: A comparison of instructional behaviors. $J$ Teach Phys Educ. 1989; 9(1): 49-31057. https://doi.org/10.1123/jtpe.9.1.49

48.Becker AJ, Wrisberg CA. Effective coaching in action: Observations of legendary collegiate basketball coach pat summitt. Sport Psychol. 2008; 22(2): 197-211. https://doi.org/10.1123/tsp.22.2.197

49.Jagiello M, Iermakov SS, Nowinski M. Differentiation of the somatic composition of students physical education specialising in various sports. Archives of Budo Science of Martial Arts and Extreme Sports. 2017;13:63-70.

50.Jagiello W, Jagiello M, Kalina RM, Barczynski BJ, Litwiniuk A, Klimczak J. Properties of body composition of female representatives of the Polish national fencing team - the sabre event. Biology of Sport. 2017;34(4):401-6. https://doi.org/10.5114/biolsport.2017.70526

51.Kriventsova I, Iermakov S, Bartik P, Nosko M, Cynarski WJ. Optimization of student-fencers' tactical training. IIdo Movement for Culture-Journal of Martial Arts Anthropology, 2017;17(3):21-30. https://doi.org/10.14589/ido.17.3.3

\section{Information about the authors:}

Cevdet C. (Corresponding author); Assoc. Prof. Dr.; http://orcid.org/0000-0002-1051-8917; cevdetcengiz@gmail.com; Department of Teaching Physical Education and Sport, Çanakkale Onsekiz Mart University; Campus, 17100, Çanakkale, Turkey.

Serbes Ş.; Assist. Prof. Dr.; http://orcid.org/0000-0002-0271-6753; serbezov@yahoo.com; Department of Teaching Physical Education and Sport, Çanakkale Onsekiz Mart University; Campus, 17100, Çanakkale, Turkey.

Erdoğan Ö.; http://orcid.org/0000-0002-7365-2048; ozgerdgn@gmail.com; Department of Teaching Physical Education and Sport, Çanakkale Onsekiz Mart University; Campus, 17100, Çanakkale, Turkey.

Dağ Ş.; http://orcid.org/0000-0003-4510-9969; senaydag.m@gmail.com; Department of Teaching Physical Education and Sport, Çanakkale Onsekiz Mart University; Campus, 17100, Çanakkale, Turkey.

Cite this article as:

Cengiz C, Serbes Ş, Erdoğan Ö, Dağ Ş. The effect of coaching behaviors on tennis players and swimmers. Pedagogics, psychology, medical-biological problems of physical training and sports, 2019;23(3):126-131. https://doi.org/10.15561/18189172.2019.0303

This is an Open Access article distributed under the terms of the Creative Commons Attribution License, which permits unrestricted use, distribution, and reproduction in any medium, provided the original work is properly cited (http://creativecommons.org/licenses/by/4.0/deed.en).

Received: 04.03.2019

Accepted: 25.04.2019; Published: 29.06.2019 